\title{
MICRORGANISMOS SOLUBILIZADORES DE FOSFATOS E O CRESCIMENTO DE PÍNUS E EUCALIPTO'(1)
}

\author{
L. ALVES ${ }^{(2)}$, E. A. MENDOZA(3) \& G. N. SILVA FILHO(4)
}

\begin{abstract}
RESUMO
Os microrganismos solubilizadores de fosfatos desempenham importante papel no suprimento de fósforo para as plantas. Isso tem motivado pesquisas em programas de inoculação controlada. 0 processo de seleção envolve várias etapas. Microrganismos isolados de cultivos de Pinuse Eucal yptus e selecionados em meio de cultura foram avaliados em 28 experimentos realizados em casa de vegetação com substrato ou solo de floresta ou de viveiro, esterilizados, sem ou com adubação fosfatada (fosfato monocálcico, fosfato de Araxá ou de Catalão). E $m$ relação à produção de matéria seca, em um experimento, hou ve efeito positivo de três isolados (177, 251 e 310A); em outro, verificou-se efeito negativo de dois isolados (177 e 261). No teor de $P$ no tecido foi verificado efeito positivo em sete tratamentos, envolvendo oito isolados $(62,177,189,198,251,262$, 310A e 310B) e dois efeitos negativos (177 e 198). Quanto ao conteúdo de $P$ na planta, foram verificados efeitos positivos em quatro experimentos, envolvendo os isolados $62,189,198,251$ e 310A. Os resultados obtidos na nutrição e no crescimento das plantas com a inoculação dos isolados 62, 189, 251 e 310A indicam a existência de potencial para ser utilizado em processos de seleção que visem à produção de inoculantes.
\end{abstract}

Termos de indexação: adubação, biofertilizante, inoculante, fósforo.

\footnotetext{
(1) Projeto financiado pela IFS - International Foudation for Science. Apresentado na FertBio2000, Santa Maria, 2000. Recebido para publicação em fevereiro de 2002 e aprovado em agosto de 2002.

(2) Mestrando em Biotecnol ogia, Centro de Ciências Biológicas, Departamento de Microbiologia e Parasitologia. U niversidade Federal Santa Catarina - UFSC. Caixa Postal 476, CEP 88010-970 Florianópolis (SC). E-mail:Icnoalves@hotmail.com

(3) Mestranda em Biotecnologia, Centro de Ciências Biológicas, Departamento de Microbiologia e Parasitologia, UFSC. E-mail:elsamendoza@bol.com.br

(4) Professor do Departamento de Microbiologia e Parasitologia, Centro de Ciências Biológicas, UFSC. E-mail:germano@ccb.ufsc.br
} 


\title{
SUMMARY: PHOSPHATE SOLUBILIZING MICROORGANISMS AND THE GROWTH OF PINE AND EUCALYPT
}

\begin{abstract}
Phosphate solubilizing microorganisms play an important role in supplying phosphorous to plants. This ability has stimulated research on plant inoculation. In our study, microorganisms were isol ated from Pinus and Eucalyptus plantations and selected in culturemedium. They werethen employed in a series of 28 experiments under greenhouse conditions in substrate, forest or sterilized nursery soil, with or without phosphate fertilization, in oneof thefol lowing P forms: cal cium phosphate, Araxá, or Catalão phosphate. Threi isol ates promoted a higher dry matter production (i sol ates 177, 251 and 310A) in one of theexperiments. However, in another experiment thei solates 177 and 261 had a negative effect on this parameter. The inoculation of 8 isol ates $(62,177,198,251,262,310 \mathrm{~A}$ and $310 B$ ) in seven of the experiments increased the $P$ concentration in plant tissues. In two experiments, the isolates 177 and 198 presented a negative effect. Phosphorous uptake was increased by the isolates 62, 189, 198, 251 and 310A, in four experiments. Results on P nutrition and growth obtained with the isol ates 62, 189, 251 and 310A indicate that these isolates possess a potential well worth of being applied in further inoculation programs aiming at inoculum production.
\end{abstract}

Index terms: fertilization, biofertilizer, inoculant, phosphorus.

\section{INTRODUÇÃO}

O fósforoéum elemento essencial às plantas, mas encontra-se em baixa disponibilidade na maioria dos sol os brasileiros (Raij, 1991). I sso torna necessário o uso de adubos fosfatados para obtenção de alta produtividade. As adubações são feitas principalmente com formas solúveis. As quantidades utilizadas são várias vezes superiores às necessidades das culturas, visto que cerca de $80 \%$ do $\mathrm{P}$ aplicado torna-se indisponível após a incorporação ao solo. O uso de fosfatos naturais é limitado, por serem as reservas nacionais constituídas princi palmente de apatitas de baixa solubilidade, o que diminui sua eficiência (Braga et al., 1991).

Dentreas alternativas que possibilitama mel horia na eficiência das fontes de fósforo, destaca-se a ação dos microrganismos sol ubilizadores (Gol dstein, 1986; Kim et al., 1998; Rodriguez \& Fraga, 1999).

No Brasil, o estudo das interações entre fosfatos e microrganismos do solo tem merecido pouca atenção. Uma grande variedade de microrganismos, como fungos dos gêner os Aspergill us e Peni cillium e bactérias dos gêneros Enterobacter e Erwinia (Kim et al., 1998; Nahas, 1999; Rodriguez \& Fraga, 1999, Whitelaw, 2000; Silva Filho \& Vidor, 2000), apresenta capacidade de solubilizar fosfatos naturais, existentes ou adicionados no solo, e os compostos de baixa solubilidade, formados após a adição de fosfatos solúveis. Dessa forma, aumentam a disponibilidade de $\mathrm{P}$ no solo e contribuem para a nutrição vegetal, aumentando o crescimento das plantas e a produtividade das culturas (Kucey, 1987; Kucey \&
Leggett, 1989; Chabot et al., 1996; Freitas et al., 1997; Kim et al., 1998; Rodrigez \& Fraga, 1999, Wahid \& Mehana, 2000; Whitelaw, 2000).

Vários sistemas de produção têm características que facilitam a introdução de microrganismos selecionados, particularmente aquel es que utilizam a produção de mudas, como os cultivos florestais. Nestes sistemas, é comum a prática da desinfecção do solo ou substrato, sendo a produção de mudas feita em sementeira no sol o ou em tubetes, utilizando pequena quantidade de substrato. Esses procedimentos reduzem a população microbiana nativa, propiciama inoculação em altas concentrações e favorecem o estabel ecimento dos microrganismos desejados.

O uso de microrganismos solubilizadores de fosfatos depende do conhecimento de suas características, dentre as quais a capacidade e o potencial de solubilização destacam-se no processo de sel eção. Essas características variam com o microrganismo e com as condições do ambiente. Dentre os fatores ambientais, o tipo de fosfato, a fonte de carbono, a fonte de nitrogênio e os teores de cálcio, ferro e potássio têm sido estudados por Silva Filho \& Vidor $(2000,2001)$ e Silva Filho et al . (2002) in vitro. No entanto, a sel eção de isolados, com al ta capacidade e potencial de sol ubilização em meios de cultura, não é garantia de sua atividade quando inoculados ao solo.

O objetivo deste trabalho foi avaliar o comportamento de microrganismos solubilizadores de fosfatos, selecionados em meios de cultura, em promover a nutrição e o crescimento de Pinus e 
Eucalyptus sob condições de solo e substrato esterilizados, em casa de vegetação.

\section{MATERIAL E MÉTODOS}

O efeito da inoculação de microrganismos solubilizadores de fosfatos na nutrição e no crescimento de espécies florestais foi avaliado em 28 experimentos, realizados em delineamento completamente casual izado com três repetições, com espécies vegetais (Pinus taeda e Eucalyptus dunnii), substratos esol os provenientes de sementeiras, sol os de florestas de duas empresas (PCC - Papel e Celulose Catarinense e RIGESA) efontes de fósforo (Quadro 1), representando as diferentes condições nas quais os isolados foram obtidos e avaliados in vitro ( Silva Filho et al., 2002).

Os isolados utilizados em cada experimento (Quadro 1) foram selecionados a partir dos resultados obtidos por Silva Filho et al. (2002), adotando-se os seguintes critérios: os cinco mel hores isolados dentre os testados (310A, 310B, 177, 262, 251); no máximo três isolados de cada espécie vegetal e local; e um escol hi do da col eção do L aboratório de Microbiol ogia do Solo do Departamento de Microbiologia e Parasitologia da Universidade Federal de Santa Catarina (o isolado 62) por sua capacidade em promover o crescimento de plantas (Narloch et al., 2002). No caso dos experimentos realizados com $E$. dunnii, em substrato da empresa RIGESA, foram utilizados tanto os isolados selecionados para substratos como para solo de floresta.

O inóculo foi produzido pelo cultivo dos isolados a $25 \pm 1{ }^{\circ} \mathrm{C}$, por 72 horas, em frasco que continha $10 \mathrm{~mL}$ de meio glicose extrato de levedura (GEL)
(Sylvester-Bradley et al., 1982; modificado por Silva Filho \& Vidor, 2000). Após este período, foram adicionados aos frascos $30 \mathrm{~mL}$ de água destilada esterilizada e procedeu-se à agitação mecânica em mesa horizontal a 300 rpm, por 5 min. As suspensões obtidas foram transferidas para frascos e armazenadas em geladeira a $4 \pm 1^{\circ} \mathrm{C}$, por 72 horas. Durante este período, foram avaliadas as unidades formadoras de colônias (UFC) por $\mathrm{mL}$ de suspensão por meio da técnica de diluição em série e cultivo em meio GEL. Após a contagem, foi feita a padronização do inóculo de forma a propiciar uma população de $10^{4} \mathrm{UFC} \mathrm{g}^{-1}$ de substrato ou solo. O inóculo foi misturado ao solo ou substrato no momento do plantio. Nos tratamentos não inoculados (testemunhas), foi utilizado igual volume da mistura das culturas esterilizadas.

Os experimentos em que se utilizou P. taeda foram também inoculados com os isolados de fungos ectomicorrízicos UFSC-Rh 90 e UFSC-Pt 41, pertencentes à coleção do Laboratório de Ectomicorrizas do Departamento de Microbiologia e Parasitologia da Universidade Federal de Santa Catarina. O inócul ofoi obtido pelo cultivo a $25 \pm 1{ }^{\circ} \mathrm{C}$, por 14 dias, de três discos de $10 \mathrm{~mm}$ de diâmetro de cada isolado, dispostos em pontos eqüidistantes em placa de Petri que continha $25 \mathrm{~mL}$ do meio "Melin Norkrans Modificado" (MNM) (Marx, 1969). A pós este período, três placas de cada fungo foram colocadas em $300 \mathrm{~mL}$ de meio MNM líquido (1/20) e trituradas em liqüidificador por três a quatro segundos. Este material foi utilizado na proporção de $1 \mathrm{~mL}$, colocado na cova de plantio junto às sementes de Pinus pré-germinadas.

Os sol os e os substratos enviados pel as empresas foram, inicialmente, penei rados em malha de $2 \mathrm{~mm}$

\section{Quadro 1. Resumo dos experimentos}

\begin{tabular}{|c|c|c|c|c|}
\hline Espécie vegetal & Empresa & $\begin{array}{l}\text { Substrato/ } \\
\text { solo/condição }\end{array}$ & Fosfato & Isolado utilizado \\
\hline \multirow[t]{4}{*}{ Pinus taeda } & PCC & Solo de viveiro & $\begin{array}{l}\text { Catalão, Araxá, Monocálcico e } \\
\text { Testemunha }\end{array}$ & $\begin{array}{l}\text { 310A, 310B, 177, 262, 251, 62, 305, } 303 \\
\text { e testemunha. }\end{array}$ \\
\hline & & Solo de floresta & $\begin{array}{l}\text { Catalão, Araxá, Monocálcico e } \\
\text { Testemunha }\end{array}$ & $\begin{array}{l}\text { 310A, 310B, 177, 262, 251, 62, 195, } 198 \\
\text { e testemunha. }\end{array}$ \\
\hline & RIGESA & Solo de viveiro & $\begin{array}{l}\text { Catalão, Araxá, Monocálcico e } \\
\text { Testemunha }\end{array}$ & $\begin{array}{l}\text { 310A, 310B, 177, 262, 251, 62, 189, } \\
264,261 \text { e testemunha. }\end{array}$ \\
\hline & & Solo de floresta & $\begin{array}{l}\text { Catalão, Araxá, Monocálcico e } \\
\text { Testemunha }\end{array}$ & $\begin{array}{l}\text { 310A, 310B, 177, 262, 251, 62, 199, } \\
308,200 \text { e testemunha. }\end{array}$ \\
\hline \multirow[t]{3}{*}{ Eucalyptus dunnii } & PCC & Substrato & $\begin{array}{l}\text { Catalão, Araxá, Monocálcico e } \\
\text { Testemunha }\end{array}$ & $\begin{array}{l}310 \mathrm{~A}, 310 \mathrm{~B}, 177,262,251,62 \mathrm{e} \\
\text { testemunha. }\end{array}$ \\
\hline & & Solo de floresta & $\begin{array}{l}\text { Catalão, Araxá, Monocálcico e } \\
\text { Testemunha }\end{array}$ & $\begin{array}{l}\text { 310A, 310B, 177, 262, 251, 62, } 307 \text { e } \\
\text { testemunha. }\end{array}$ \\
\hline & RIGESA & Substrato & $\begin{array}{l}\text { Catalão, Araxá, Monocálcico e } \\
\text { Testemunha }\end{array}$ & $\begin{array}{l}310 A, 310 B, 177,262,251,62,190, \\
191,201,269,309 \text { e testemunha. }\end{array}$ \\
\hline
\end{tabular}


de abertura e, em seguida, desinfectados em autoclave a $120^{\circ} \mathrm{C}$, durante $20 \mathrm{~min}$, por três vezes consecutivas a interval os de 24 horas. O substrato utilizado na empresa PCC era constituído de uma mistura de 3:2:1 (v:v:v) de pó de xaxim, turfa e casca de pínus decomposta e o da empresa RIGESA era um produto comercial (Plantmax $\left.{ }^{\circledR}\right)$. Cada unidade experimental foi constituída de um vaso com $200 \mathrm{~g}$ de substrato ou solo e mantida em $80 \%$ da capaci dade de campo durante o período experimental. Os substratos ou sol os foram suplementados ou não no momento do plantio com fosfato e demais nutrientes, conforme os procedimentos e quantidades utilizados em cada empresa (Quadro 2).

As sementes (eucalipto e pínus) foram desinfectadas com álcool $70 \%$, durante 30 segundos, e hipoclorito de sódio a $2 \%$, durante 20 min; em seguida, receberam lavagens sucessivas com água destilada esterilizada. As sementes de Pinus sofreram quebra de dormência, resultante da imersão das sementes em água, durante 24 horas, à temperatura de 2 a $5{ }^{\circ} \mathrm{C}$. A pós este período, eliminaram-se as sementes sobrenadantes juntamente com a água. As sementes foram acondicionadas em sacos de polietileno e mantidas em temperatura de 2 a $5^{\circ} \mathrm{C}$, durante 18 dias, sendo agitadas diariamente. Após, as sementes foram colocadas para germinar em placas de Petri que continham o meio GEL. Em cada vaso, foram adicionadas cinco sementes pré-germinadas e, após a emergência, foram deixadas duas plantas por vaso.

As plantas de Eucalyptus e Pinus foram cultivadas em casa de vegetação por 90 e 120 dias, respectivamente. No final desse período, foram col hidas, secas a $72{ }^{\circ} \mathrm{C}$, para determinação do peso da matéria seca da parteaérea, moídas e analisadas quanto ao teor de fósforo, adotando-se o procedimento proposto por Tedesco et al. (1995).

Os dados foram submetidos à análise de variância, eas médias foram comparadas pel o teste deTukey a $5 \%$.

\section{RESULTADOS E DISCUSSÃO}

Os resultados obtidos na produção dematéria seca (Quadro 3), teor de fósforo (Quadro 4) e conteúdo de fósforo na parteaérea (Quadro 5), nos 28 experimentos realizados, foram classificados em quatro grupos:

a) sem efeito;

b) diferenças entre os isolados, mas sem diferença da testemunha;

c) efeito negativo da inoculação;

d) efeito positivo da inoculação.

Em relação à produção de matéria seca, não houve efeito da inoculação em 23 dos experimentos (Quadro 3). Em três experimentos, houve diferenças entre os isolados; no entanto, esses não diferiram da testemunha. Em um experimento, foi encontrado efeito negativo da inoculação de dois isol ados (177 e 261): no cultivo de $P$. taeda com solo de viveiro da RIGESA na presença de fosfato de Catalão. Três isolados (310A, 177 e 251) promoveram a produção de matéria seca de $E$. dunnii cultivado com solo de floresta da empresa PCC suplementado com fosfato de Catalão.

A inoculação não alterou o teor de fósforo no tecido vegetal em 13 dos 28 experimentos real izados (Quadro 4). Em outros sete experimentos, houve efeito positivo da inoculação no teor de fósforo da parte aérea das plantas: com os isolados 251 e 262, respectivamente, na presença de fosfato de Catalão e de Araxá com solo de viveiro da empresa PCC cultivado com P. taeda; na mesma condição de espécie vegetal e empresa com solo de floresta e fosfato de Catalão, com os isolados 310B e 198; com a mesma espécie com solo de vivieiro da empresa RIGESA, com os isolados 310A, 310B e 62, na presença de fosfato de Catalão, 310B, 251, 62 e 189, de fosfato monocálcico, e $310 \mathrm{~A}$ e 189, na testemunha; e com o isolado 177 em E. dunni com substrato da RIGESA sem fósforo (testemunha).

\section{Quadro 2. Quantidades de fertilizantes utilizadas em $\mathbf{2 0 0} \mathbf{g}$ de solo ou substrato}

\begin{tabular}{|c|c|c|c|c|c|c|}
\hline \multirow{2}{*}{ Empresa } & \multirow{2}{*}{ Espécie vegetal } & \multirow{2}{*}{ Condição } & \multicolumn{4}{|c|}{ Fertilizante (g) } \\
\hline & & & Fosf. natural & Fosf. monocálcico & $\mathrm{NH}_{4} \mathrm{NO}_{3}$ & $\mathrm{KCl}$ \\
\hline \multirow[t]{4}{*}{ PCC } & Pinus taeda & Solo de floresta & 3,37 & 0,56 & 0,23 & 0,10 \\
\hline & & Solo de viveiro & 3,37 & 0,56 & 0,23 & 0,10 \\
\hline & Eucalyptus dunnii & Solo de floresta & 3,37 & 0,56 & 0,23 & 0,10 \\
\hline & & Substrato & 3,37 & 0,56 & 0,23 & 0,10 \\
\hline \multirow[t]{3}{*}{ RIGESA } & Pinus taeda & Solo de floresta & 1,33 & 0,23 & 0,10 & 0,05 \\
\hline & & Solo de viveiro & 1,33 & 0,23 & 0,10 & 0,05 \\
\hline & Eucalyptus dunnii & Substrato & 1,14 & 0,10 & 0,49 & 0,14 \\
\hline
\end{tabular}


Quadro 3. Matéria seca da parte aérea de Pinus taeda (Pt) e Eucaluptus dunnii (E d), cultivados em solo (So) e substrato (Su) provenientes de viveiro (V) e floresta (F) de duas empresas florestais de Santa Catarina (PCC e RIGESA), com diferentes fontes de fósforo e inoculados com microrganismos solubilizadores de fosfatos ${ }^{(1)}$

\begin{tabular}{|c|c|c|c|c|c|c|c|c|c|c|c|c|c|}
\hline \multirow{2}{*}{$\begin{array}{l}\text { Condição } \\
\text { experimental }\end{array}$} & \multirow[t]{2}{*}{ Fosfato } & \multicolumn{12}{|c|}{ I solado } \\
\hline & & $310 \mathrm{~A}$ & $310 \mathrm{~B}$ & 177 & 262 & 251 & 62 & 305 & 303 & & & & Test. \\
\hline $\begin{array}{l}\text { Pt So V } \\
\text { PCC }\end{array}$ & $\begin{array}{l}\text { Catalão } \\
\text { Araxá } \\
\text { Monocál cico } \\
\text { Testemunha }\end{array}$ & $\begin{array}{l}0,15 \\
0,12 \\
0,10 \\
0,11\end{array}$ & $\begin{array}{l}0,11 \\
0,09 \\
0,08 \\
0,14\end{array}$ & $\begin{array}{l}0,07 \\
0,13 \\
0,04 \\
0,19\end{array}$ & $\begin{array}{l}0,14 \\
0,03 \\
0,15 \\
0,08\end{array}$ & $\begin{array}{l}0,03 \\
0,21 \\
0,08 \\
0,20\end{array}$ & $\begin{array}{l}0,10 \\
0,12 \\
0,06 \\
0,11\end{array}$ & $\begin{array}{l}0,05 \\
0,00 \\
0,05 \\
0,09\end{array}$ & $\begin{array}{l}0,06 \\
0,08 \\
0,14 \\
0,18\end{array}$ & & & & $\begin{array}{l}0,07 \\
0,11 \\
0,11 \\
0,14\end{array}$ \\
\hline & & $310 \mathrm{~A}$ & 310B & 177 & 262 & 251 & 62 & 195 & 198 & & & & Test. \\
\hline $\begin{array}{l}\text { Pt So F } \\
\text { PCC }\end{array}$ & $\begin{array}{l}\text { Catalão } \\
\text { Araxá } \\
\text { Monocálcico } \\
\text { Testemunha }\end{array}$ & $\begin{array}{l}0,30 \\
0,32 \\
0,50 \\
0,32\end{array}$ & $\begin{array}{l}0,22 \\
0,33 \\
0,69 \\
0,29\end{array}$ & $\begin{array}{l}0,27 \\
0,40 \\
0,64 \\
0,30\end{array}$ & $\begin{array}{l}0,35 \\
0,30 \\
0,86 \\
0,27\end{array}$ & $\begin{array}{l}0,33 \\
0,34 \\
0,53 \\
0,26\end{array}$ & $\begin{array}{l}0,34 \\
0,40 \\
0,64 \\
0,34\end{array}$ & $\begin{array}{l}0,20 \\
0,35 \\
0,63 \\
0,34\end{array}$ & $\begin{array}{l}0,32 \\
0,33 \\
0,56 \\
0,27\end{array}$ & & & & $\begin{array}{l}0,11 \\
0,29 \\
0,63 \\
0,19\end{array}$ \\
\hline $\begin{array}{l}\text { Ed Su V } \\
\text { PCC }\end{array}$ & $\begin{array}{l}\text { Catalão } \\
\text { Araxá } \\
\text { Monocál cico } \\
\text { Testemunha }\end{array}$ & $\begin{array}{l}310 \mathrm{~A} \\
1,25 \\
1,29 \\
0,83 \\
1,36\end{array}$ & $\begin{array}{l}310 \mathrm{~B} \\
1,39 \\
1,64 \\
2,07 \\
1,33\end{array}$ & $\begin{array}{c}177 \\
0,91 \\
0,78 \\
0,96 \\
0,36\end{array}$ & $\begin{array}{c}262 \\
0,56 \\
0,86 \\
1,18 \\
1,02\end{array}$ & $\begin{array}{r}251 \\
1,54 \\
1,23 \\
1,14 \\
1,19\end{array}$ & $\begin{array}{r}62 \\
1,59 \\
1,64 \\
1,77 \\
1,27\end{array}$ & & & & & & $\begin{array}{l}\text { Test. } \\
1,32 \\
2,10 \\
1,18 \\
1,18\end{array}$ \\
\hline $\begin{array}{l}\text { Ed So F } \\
\text { PCC }\end{array}$ & $\begin{array}{l}\text { Catalão } \\
\text { Araxá } \\
\text { Monocál cico } \\
\text { Testemunha }\end{array}$ & \begin{tabular}{l}
\multicolumn{1}{c}{$310 A$} \\
$0,59 a b$ \\
0,20 \\
2,56 \\
0,04
\end{tabular} & $\begin{array}{l}310 \mathrm{~B} \\
0,48 \mathrm{ac} \\
0,05 \\
2,78 \\
0,04\end{array}$ & \begin{tabular}{l}
\multicolumn{1}{c}{177} \\
$0,55 a b$ \\
0,03 \\
2,43 \\
0,02
\end{tabular} & \begin{tabular}{l}
\multicolumn{1}{c}{262} \\
0,12 bc \\
0,02 \\
2,41 \\
0,03
\end{tabular} & \begin{tabular}{l}
\multicolumn{1}{c}{251} \\
$0,72 a$ \\
0,04 \\
2,71 \\
0,02
\end{tabular} & \begin{tabular}{l}
\multicolumn{1}{c}{62} \\
0,24 ac \\
0,08 \\
2,76 \\
0,02
\end{tabular} & \begin{tabular}{l}
\multicolumn{1}{c}{307} \\
$0,20 \mathrm{bc}$ \\
0,04 \\
2,79 \\
0,02
\end{tabular} & & & & & $\begin{array}{l}\text { Test. } \\
0,07 \text { c } \\
0,03 \\
2,58 \\
0,04\end{array}$ \\
\hline $\begin{array}{l}\text { Pt So V } \\
\text { RIGESA }\end{array}$ & $\begin{array}{l}\text { Catalão } \\
\text { Araxá } \\
\text { Monocálcico } \\
\text { Testemunha }\end{array}$ & \begin{tabular}{l}
\multicolumn{1}{c}{$310 \mathrm{~A}$} \\
0,39 ad \\
0,25 \\
0,76 \\
$0,47 \mathrm{a}$
\end{tabular} & $\begin{array}{l}310 \mathrm{~B} \\
0,43 \mathrm{ad} \\
0,47 \\
0,80 \\
0,34 \mathrm{ab}\end{array}$ & \begin{tabular}{l}
\multicolumn{1}{c}{177} \\
$0,32 \mathrm{~cd}$ \\
0,32 \\
0,55 \\
$0,41 \mathrm{ab}$
\end{tabular} & \begin{tabular}{l}
\multicolumn{1}{c}{262} \\
$0,33 \mathrm{bd}$ \\
0,53 \\
0,55 \\
$0,19 \mathrm{~b}$
\end{tabular} & \begin{tabular}{l}
\multicolumn{1}{c}{251} \\
$0,53 a$ \\
0,50 \\
0,50 \\
$0,46 a$
\end{tabular} & \begin{tabular}{l}
\multicolumn{1}{c}{62} \\
0,44 ad \\
0,39 \\
0,51 \\
0,45 a
\end{tabular} & \begin{tabular}{l}
\multicolumn{1}{c}{189} \\
$0,42 \mathrm{ad}$ \\
0,51 \\
0,57 \\
$0,46 \mathrm{a}$
\end{tabular} & \begin{tabular}{l}
\multicolumn{1}{c}{264} \\
$0,48 \mathrm{ac}$ \\
0,44 \\
0,61 \\
$0,52 \mathrm{a}$
\end{tabular} & \begin{tabular}{l}
\multicolumn{1}{c}{261} \\
$0,26 \mathrm{~d}$ \\
0,42 \\
0,57 \\
$0,50 \mathrm{a}$
\end{tabular} & & & $\begin{array}{l}\text { Test. } \\
0,52 \mathrm{ab} \\
0,34 \\
0,56 \\
0,40 \mathrm{ab}\end{array}$ \\
\hline $\begin{array}{l}\text { Pt So F } \\
\text { RIGESA }\end{array}$ & $\begin{array}{l}\text { Catalão } \\
\text { Araxá } \\
\text { Monocálcico } \\
\text { Testemunha }\end{array}$ & \begin{tabular}{l}
\multicolumn{1}{c}{$310 \mathrm{~A}$} \\
0,30 \\
$0,25 a b$ \\
$0,33 a$ \\
0,28
\end{tabular} & $\begin{array}{l}310 \mathrm{~B} \\
0,29 \\
0,27 \mathrm{ab} \\
0,36 \mathrm{a} \\
0,27\end{array}$ & \begin{tabular}{l}
\multicolumn{1}{c}{177} \\
0,18 \\
$0,29 a$ \\
$0,27 a b$ \\
0,30
\end{tabular} & \begin{tabular}{l}
\multicolumn{1}{c}{262} \\
0,16 \\
$0,28 \mathrm{ab}$ \\
$0,14 \mathrm{~b}$ \\
0,20
\end{tabular} & \begin{tabular}{l}
\multicolumn{1}{c}{251} \\
0,11 \\
$0,06 \mathrm{~b}$ \\
$0,21 \mathrm{ab}$ \\
0,18
\end{tabular} & \begin{tabular}{l}
\multicolumn{1}{c}{62} \\
0,20 \\
$0,28 a b$ \\
$0,26 a b$ \\
0,18
\end{tabular} & $\begin{array}{l}199 \\
0,22 \\
0,25 a b \\
0,29 a b \\
0,24\end{array}$ & \begin{tabular}{l}
\multicolumn{1}{c}{308} \\
0,21 \\
$0,16 a b$ \\
$0,19 a b$ \\
0,24
\end{tabular} & \begin{tabular}{l}
\multicolumn{1}{c}{200} \\
0,15 \\
$0,27 a b$ \\
$0,19 a b$ \\
0,09
\end{tabular} & & & $\begin{array}{l}\text { Test. } \\
0,28 \\
0,25 a b \\
0,24 a b \\
0,20\end{array}$ \\
\hline $\begin{array}{l}\text { Ed Su V } \\
\text { RIGESA }\end{array}$ & $\begin{array}{l}\text { Catalão } \\
\text { Araxá } \\
\text { Monocál cico } \\
\text { Testemunha }\end{array}$ & $\begin{array}{l}310 A \\
6,92 \\
9,37 \\
7,25 \\
3,42\end{array}$ & $\begin{array}{l}310 B \\
6,51 \\
4,80 \\
7,25 \\
7,78\end{array}$ & $\begin{array}{r}177 \\
5,68 \\
3,19 \\
4,68 \\
7,50\end{array}$ & $\begin{array}{c}262 \\
7,50 \\
7,10 \\
4,66 \\
7,14\end{array}$ & $\begin{array}{r}251 \\
4,19 \\
7,18 \\
6,87 \\
6,97\end{array}$ & $\begin{array}{r}62 \\
0,00 \\
5,30 \\
6,50 \\
9,32\end{array}$ & $\begin{array}{c}190 \\
2,57 \\
2,21 \\
6,39 \\
6,97\end{array}$ & $\begin{array}{c}191 \\
3,99 \\
4,50 \\
2,20 \\
6,36\end{array}$ & $\begin{array}{r}201 \\
7,79 \\
8,65 \\
6,20 \\
7,66\end{array}$ & $\begin{array}{l}269 \\
5,44 \\
5,63 \\
4,56 \\
6,75\end{array}$ & $\begin{array}{r}309 \\
7,33 \\
8,12 \\
6,53 \\
8,55\end{array}$ & $\begin{array}{l}\text { Test. } \\
6,09 \\
9,11 \\
8,88 \\
9,63\end{array}$ \\
\hline
\end{tabular}

(1) Médias seguidas de letras diferentes, na mesma linha, diferem significativamente a $5 \%$ de probabilidade pelo teste de Tukey. Ausência de letras indica diferença não-significativa. As letras ac referem-se ao conjunto abc, ad a abcd e assim por diante.

Em duas oportunidades, foram verificados efeitos negativos da inoculação: com os isolados 198 e 177 cultivados com P. taeda na presença de fosfato de Araxá com solo de floresta da PCC e de viveiro da RIGESA, respectivamente.

O conteúdo de fósforo na parte aérea não foi influenciado pela inoculação em 14 dos 28 experimentos realizados (Quadro 5). Em 10 experimentos, foram observados efeitos apenas entre os isolados que não diferiram da testemunha. Efeitos positivos da inoculação na quantidade de fósforo presente na parte aérea das plantas foram encontrados em quatro experimentos: com os isolados 310A, 251, 62 e 198, inoculados em solo de floresta da PCC na presença de fosfato de Catalão; com os isolados 251 e62, inoculados em sol o defloresta da PCC cultivado com E. dunnii em fosfato de Catalão e na testemunha, respectivamente, e com os isolados 310A 
Quadro 4. Teor deP na matéria seca da parteaérea de Pinus taeda (Pt) e Eucaluptus dunnii (E d), cultivados em solo (So) e substrato (Su) provenientes de viveiro (V) e floresta (F) de duas empresa florestais de Santa Catarina (PCC e RIGESA), com diferentes fontes de fósforo e inoculados com microrganismos solubilizadores de fosfatos ${ }^{(1)}$

\begin{tabular}{|c|c|c|c|c|c|c|c|c|c|c|c|c|c|}
\hline \multirow[t]{2}{*}{$\begin{array}{l}\text { Condição } \\
\text { experimental }\end{array}$} & \multirow[t]{2}{*}{ Fosfato } & \multicolumn{12}{|c|}{ I solado } \\
\hline & & $310 \mathrm{~A}$ & $310 \mathrm{~B}$ & 177 & 262 & 251 & 62 & 305 & 303 & & & & Test. \\
\hline \multirow[t]{2}{*}{$\begin{array}{l}\text { Pt So V } \\
\text { PCC }\end{array}$} & $\begin{array}{l}\text { Catalão } \\
\text { Araxá } \\
\text { Monocálcico } \\
\text { Testemunha }\end{array}$ & $\begin{array}{l}0,2 \mathrm{~b} \\
0,4 \mathrm{~b} \\
1,0 \\
0,6\end{array}$ & $\begin{array}{l}0,7 \mathrm{ab} \\
0,5 \mathrm{~b} \\
2,8 \\
0,8\end{array}$ & $\begin{array}{l}0,6 a b \\
0,8 b \\
1,2 \\
0,9\end{array}$ & $\begin{array}{l}0,8 a b \\
2,6 a \\
1,0 \\
0,9\end{array}$ & $\begin{array}{l}3,8 \mathrm{a} \\
0,5 \mathrm{~b} \\
2,2 \\
2,4\end{array}$ & $\begin{array}{l}3,2 \mathrm{ab} \\
1,1 \mathrm{~b} \\
3,1 \\
0,9\end{array}$ & $\begin{array}{l}0,4 \mathrm{~b} \\
0,0 \mathrm{~b} \\
0,6 \\
0,6\end{array}$ & $\begin{array}{l}0,6 \mathrm{ab} \\
0,0 \mathrm{~b} \\
0,8 \\
0,0\end{array}$ & & & & $\begin{array}{l}0,2 \mathrm{~b} \\
0,8 \mathrm{~b} \\
1,2 \\
0,6\end{array}$ \\
\hline & & $310 \mathrm{~A}$ & $310 \mathrm{~B}$ & 177 & 262 & 251 & 62 & 195 & 198 & & & & Test. \\
\hline \multirow[t]{2}{*}{$\begin{array}{l}\text { Pt So F } \\
\text { PCC }\end{array}$} & $\begin{array}{l}\text { Catalão } \\
\text { Araxá } \\
\text { Monocálcico } \\
\text { Testemunha }\end{array}$ & $\begin{array}{l}0,6 a b \\
0,5 a c \\
0,8 a b \\
0,5\end{array}$ & $\begin{array}{l}0,6 \mathrm{a} \\
0,5 \mathrm{bc} \\
0,9 \mathrm{ab} \\
0,4\end{array}$ & $\begin{array}{l}0,6 a b \\
0,8 a \\
0,7 a b \\
0,6\end{array}$ & $\begin{array}{l}0,5 a b \\
0,5 a c \\
0,7 a b \\
0,6\end{array}$ & $\begin{array}{l}0,5 a b \\
0,6 a b \\
0,6 a b \\
0,5\end{array}$ & $\begin{array}{l}0,6 a b \\
0,6 a b \\
0,9 a \\
0,6\end{array}$ & $\begin{array}{l}0,4 \mathrm{ab} \\
0,5 \mathrm{bc} \\
0,6 \mathrm{~b} \\
0,4\end{array}$ & $\begin{array}{l}0,6 a \\
0,3 c \\
0,7 a b \\
0,5\end{array}$ & & & & $\begin{array}{l}0,3 b \\
0,6 a b \\
0,7 a b \\
0,4\end{array}$ \\
\hline & & $310 \mathrm{~A}$ & $310 \mathrm{~B}$ & 177 & 262 & 251 & 62 & & & & & & Test. \\
\hline $\begin{array}{l}\text { Ed Su V } \\
\text { PCC }\end{array}$ & $\begin{array}{l}\text { Catalão } \\
\text { Araxá } \\
\text { Monocálcico } \\
\text { Testemunha }\end{array}$ & $\begin{array}{l}2,1 \\
2,4 \\
2,3 \\
2,8\end{array}$ & $\begin{array}{l}2,9 \\
2,4 \\
2,5 \\
2,4\end{array}$ & $\begin{array}{l}2,4 \\
2,2 \\
3,4 \\
2,7\end{array}$ & $\begin{array}{l}2,6 \\
3,5 \\
4,1 \\
3,5\end{array}$ & $\begin{array}{l}2,8 \\
2,8 \\
3,9 \\
2,0\end{array}$ & $\begin{array}{l}2,3 \\
2,3 \\
2,7 \\
2,6\end{array}$ & & & & & & $\begin{array}{l}2,5 \\
2,8 \\
3,0 \\
1,9\end{array}$ \\
\hline \multirow[t]{2}{*}{$\begin{array}{l}\text { Ed So F } \\
\text { PCC }\end{array}$} & $\begin{array}{l}\text { Catalão } \\
\text { Araxá } \\
\text { Monocálcico } \\
\text { Testemunha }\end{array}$ & $\begin{array}{l}310 A \\
0,9 \\
0,8 a b \\
1,2 \\
1,6 a b\end{array}$ & $\begin{array}{l}310 \mathrm{~B} \\
0,8 \\
0,6 \mathrm{ab} \\
1,1 \\
0,7 \mathrm{ab}\end{array}$ & $\begin{array}{l}177 \\
1,2 \\
2,0 a b \\
1,2 \\
3,6 a b\end{array}$ & \begin{tabular}{l}
\multicolumn{1}{c}{262} \\
1,1 \\
$5,4 a$ \\
1,0 \\
$3,8 a b$
\end{tabular} & $\begin{array}{l}251 \\
1,8 \\
0,0 \mathrm{~b} \\
1,6 \\
0,0 \mathrm{~b}\end{array}$ & \begin{tabular}{l}
\multicolumn{1}{c}{62} \\
1,7 \\
$1,4 \mathrm{ab}$ \\
1,3 \\
$9,4 \mathrm{a}$
\end{tabular} & $\begin{array}{l}307 \\
1,2 \\
3,2 \mathrm{ab} \\
0,9 \\
2,3 \mathrm{ab}\end{array}$ & & & & & $\begin{array}{l}\text { Test. } \\
1,4 \\
2,2 \mathrm{ab} \\
1,6 \\
1,4 \mathrm{ab}\end{array}$ \\
\hline & & $310 \mathrm{~A}$ & $310 \mathrm{~B}$ & 177 & 262 & 251 & 62 & 189 & 264 & 261 & & & Test. \\
\hline \multirow[t]{2}{*}{$\begin{array}{l}\text { Pt So V } \\
\text { RIGESA }\end{array}$} & $\begin{array}{l}\text { Catalão } \\
\text { Araxá } \\
\text { Monocálcico } \\
\text { Testemunha }\end{array}$ & $\begin{array}{l}0,6 \mathrm{ab} \\
0,5 \mathrm{bc} \\
0,6 \mathrm{ad} \\
0,7 \mathrm{a}\end{array}$ & $\begin{array}{l}0,7 \mathrm{a} \\
0,5 \mathrm{ac} \\
0,7 \mathrm{ab} \\
0,5 \mathrm{ac}\end{array}$ & $\begin{array}{l}0,4 \text { de } \\
0,3 \mathrm{~d} \\
0,3 \mathrm{e} \\
0,4 \mathrm{c}\end{array}$ & $\begin{array}{l}0,5 \mathrm{~cd} \\
0,5 \mathrm{bc} \\
0,5 \mathrm{ce} \\
0,4 \mathrm{bc}\end{array}$ & $\begin{array}{l}0,5 \mathrm{ad} \\
0,6 \mathrm{a} \\
0,8 \mathrm{a} \\
0,5 \mathrm{ac}\end{array}$ & $\begin{array}{l}0,6 \mathrm{ac} \\
0,6 \mathrm{ab} \\
0,6 \mathrm{ac} \\
0,5 \mathrm{ac}\end{array}$ & $\begin{array}{l}0,5 \mathrm{bd} \\
0,5 \mathrm{ac} \\
0,7 \mathrm{ab} \\
0,6 \mathrm{ab}\end{array}$ & $\begin{array}{l}0,3 \mathrm{e} \\
0,4 \mathrm{~cd} \\
0,4 \mathrm{e} \\
0,4 \mathrm{c}\end{array}$ & $\begin{array}{l}0,5 \mathrm{ad} \\
0,5 \mathrm{ac} \\
0,6 \mathrm{ad} \\
0,5 \mathrm{ac}\end{array}$ & & & $\begin{array}{l}0,4 \mathrm{de} \\
0,5 \mathrm{ac} \\
0,4 \mathrm{de} \\
0,4 \mathrm{c}\end{array}$ \\
\hline & & $310 \mathrm{~A}$ & $310 \mathrm{~B}$ & 177 & 262 & 251 & 62 & 199 & 308 & 200 & & & Test. \\
\hline \multirow[t]{2}{*}{$\begin{array}{l}\text { Pt So F } \\
\text { RIGESA }\end{array}$} & $\begin{array}{l}\text { Catalão } \\
\text { Araxá } \\
\text { Monocálcico } \\
\text { Testemunha }\end{array}$ & $\begin{array}{l}0,5 a b \\
0,6 a b \\
0,6 \\
0,6\end{array}$ & $\begin{array}{l}0,5 a b \\
0,6 a b \\
0,7 \\
0,6\end{array}$ & $\begin{array}{l}0,6 a b \\
0,5 a b \\
0,6 \\
0,4\end{array}$ & $\begin{array}{l}0,5 a b \\
0,5 a b \\
0,6 \\
0,4\end{array}$ & $\begin{array}{l}0,3 b \\
0,1 b \\
0,8 \\
0,4\end{array}$ & $\begin{array}{l}0,07 a \\
0,06 a b \\
0,7 \\
1,0\end{array}$ & $\begin{array}{l}0,05 a b \\
0,07 a b \\
0,7 \\
0,5\end{array}$ & $\begin{array}{l}0,06 a b \\
0,04 a b \\
0,6 \\
0,6\end{array}$ & $\begin{array}{l}0,9 \mathrm{a} \\
0,8 \mathrm{a} \\
0,6 \\
0,4\end{array}$ & & & $\begin{array}{l}0,6 a b \\
0,7 a b \\
0,7 \\
0,7\end{array}$ \\
\hline & & $310 \mathrm{~A}$ & $310 \mathrm{~B}$ & 177 & 262 & 251 & 62 & 190 & 191 & 201 & 269 & 309 & Test. \\
\hline $\begin{array}{l}\text { Ed Su V } \\
\text { RIGESA }\end{array}$ & $\begin{array}{l}\text { Catalão } \\
\text { Araxá } \\
\text { Monocálcico } \\
\text { Testemunha }\end{array}$ & $\begin{array}{l}2,4 \\
1,5 \\
2,3 \mathrm{ab} \\
0,6 \mathrm{c}\end{array}$ & $\begin{array}{l}4,4 \\
3,0 \\
4,4 a \\
2,9 a b\end{array}$ & $\begin{array}{l}2,5 \\
0,4 \\
1,0 \mathrm{~b} \\
3,6 \mathrm{a}\end{array}$ & $\begin{array}{l}3,5 \\
2,7 \\
1,7 \mathrm{ab} \\
1,3 \mathrm{bc}\end{array}$ & $\begin{array}{l}2,9 \\
2,2 \\
2,4 a b \\
2,6 a b\end{array}$ & $\begin{array}{l}0,0 \\
1,5 \\
3,0 \mathrm{ab} \\
1,8 \mathrm{ac}\end{array}$ & $\begin{array}{l}1,2 \\
3,4 \\
2,3 a b \\
3,1 a b\end{array}$ & $\begin{array}{l}2,2 \\
2,0 \\
1,1 \mathrm{~b} \\
1,7 \mathrm{ac}\end{array}$ & $\begin{array}{l}3,8 \\
2,0 \\
1,8 \mathrm{ab} \\
2,5 \mathrm{ac}\end{array}$ & $\begin{array}{l}1,5 \\
1,2 \\
1,4 \mathrm{~b} \\
2,1 \mathrm{ac}\end{array}$ & $\begin{array}{l}2,0 \\
2,2 \\
0,9 \mathrm{~b} \\
2,4 \mathrm{ac}\end{array}$ & $\begin{array}{l}1,8 \\
2,2 \\
3,6 \mathrm{ab} \\
1,6 \mathrm{bc}\end{array}$ \\
\hline
\end{tabular}

(1) Médias seguidas de letras diferentes, na mesma, linha diferem significativamente a $5 \%$ de probabilidade pelo teste de Tukey. Ausência de letras indica diferença não-significativa. As letras ac referem-se ao conjunto abc, ad a abcd e assim por diante.

e 189, inoculados em solo de viveiro da RIGESA na testemunha cultivada com P. taeda.

Apesar da baixa incidência de efeitos positivos da inoculação, os resultados foram bastante promissores à medida que foram efetuadas análises mais detalhadas dos resultados. Alguns isolados apresentaram efeitos negativos sobre os parâmetros avaliados. Resultados destetipojá eram esperados, uma vez que a característica utilizada na seleção destes microrganismos foi apenas a capacidade e 0 potencial de solubilizar fosfatos. A não-utilização de outra característica não impede que o microrganismotenha características prejudiciais às plantas. Gêneros citados na literatura como solubilizadores de fosfatos, tais como: Fusarium, Rhizoctonia e Pythi um (Eira, 1992; Whitelaw, 2000) apresentam espécies patogêni cas aos vegetais, sendo parasitas não especializados ou saprófitos fracos 
Quadro 5. Conteúdo de fósforo na matéria seca da parte aérea de Pinus taeda (Pt) e Eucaluptus dunnii (E d), cultivados em solo (So) e substrato (Su) provenientes de viveiro (V) e floresta (F) de duas empresa florestais de Santa Catarina (PCC e RIGESA), com diferentes fontes de fósforo e inoculados com microrganismos solubilizadores de fosfatos ${ }^{(1)}$

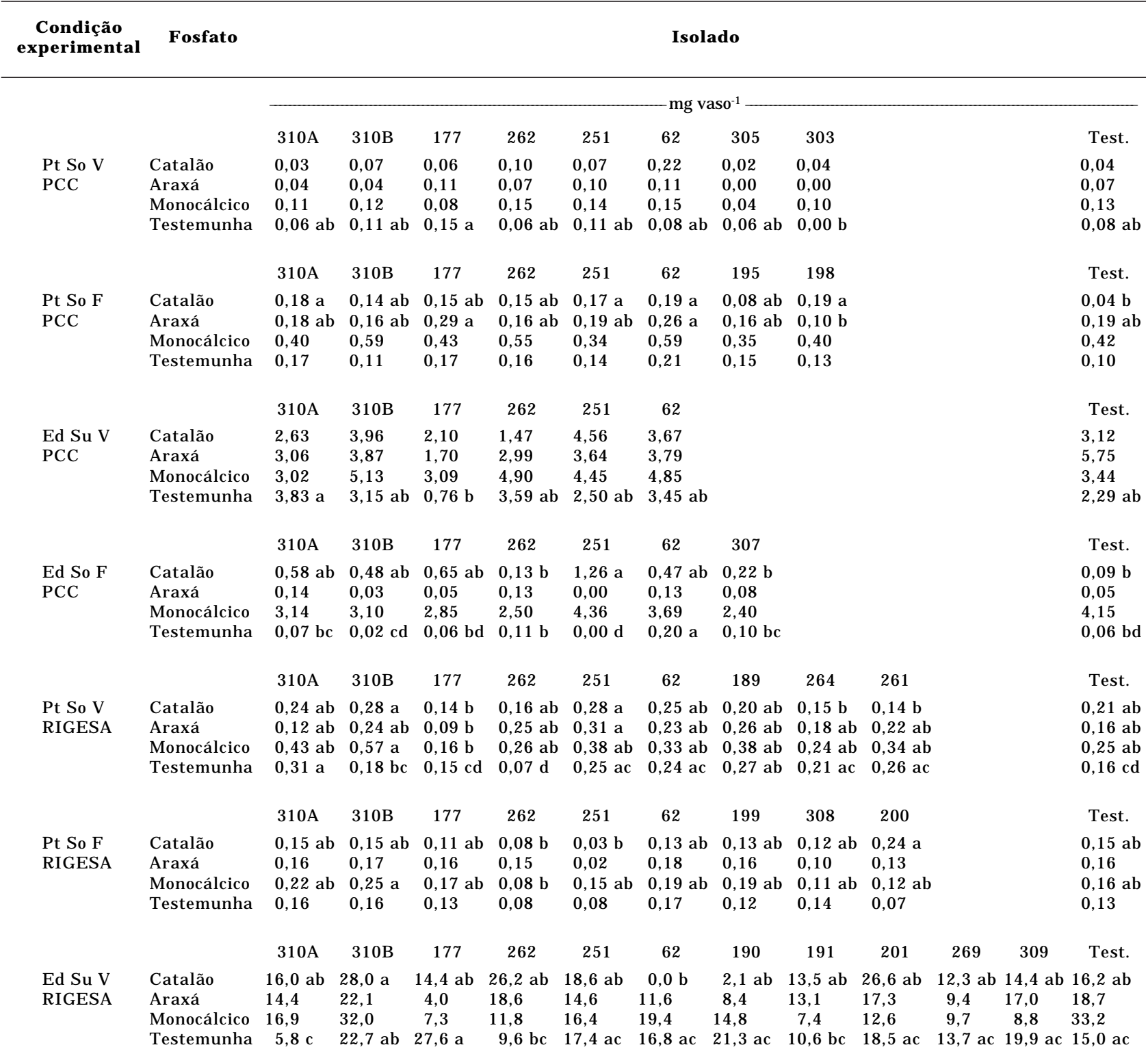

${ }^{(1)}$ Médias seguidas de letras diferentes, na mesma linha, diferem significativamente a $5 \%$ de probabilidade pelo teste de Tukey. Ausência de letras indica diferença não-significativa. As letras ac referem-se ao conjunto abc, ad a abcd e assim por diante.

(Cardoso, 1992). Os isolados que provocaram efeitos negativos apresentam características morfológicas que os identificam como pertencentes aos gêneros Penicillium (177 e 261) e Aspergillus (198). Esses gêneros geralmente não apresentam problemas de fitopatogenicidade, sendo considerados como saprófitas obrigatórios (Cardoso, 1992). No entanto, isso não impede que, em certas circunstâncias, possam produzir substâncias tóxicas em níveis críticos para as plantas ou mesmo que venham a crescer excessivamente, competindo com a planta por nutrientes. Narloch et al. (2002) verificaram que um isolado de Aspergillus só tinha efeito positivo no crescimento de rabanete em altas dosagens de fósforo, quando não havia mais competição pelo elemento.

O comportamento dos isol ados 198 e 177 não pôde ser devidamente interpretado. O isolado 177 
apresentou efeitos negativos e positivos, tanto na produção de matéria seca como no teor de fósforo em situações bem diferentes de espécies de plantas (P. taeda e E. dunnii) e fontes de fosfato (Catalão, Araxá e testemunha), não permitindo o estabelecimento de nenhuma relação e conclusão sobre os fatores que levaram a esses resultados. Embora os efeitos negativos tenham ocorrido no crescimento e no teor de fósforo no tecido, não foi detectado efeito negativo no conteúdo de $\mathrm{P}$ das plantas.

O efeito positivo da inoculação deal guns isolados na produção de matéria seca foi da ordem de oito a 10 vezes (310A e 251, respectivamente) (Quadro 3) e na quantidade de fósforo presente na parte aérea das plantas de quatro a 14 vezes com o isolado 251, de duas a cinco vezes com o isolado 310A, de três a cinco vezes com o isolado 62, e de duas vezes com o isolado 189 (Quadro 5), demonstrando o potencial destes isolados.

O efeito da inoculação de microrganismos solubilizadores de fosfatos sobre o crescimento de plantas tem sido verificado por vários autores que apresentam resultados semel hantes aos obtidos neste trabalho. Em recente revisão sobre o tema, Whitelaw (2000) cita aumentos que variam de dois a 93 \% na produção de matéria seca e detrês a 383 \% na absorção de fósforo. Em alguns trabalhos, os efeitos ocorrem em todos os parâmetros avaliados (Taha et al., 1969; Kundu \& Gaur, 1984; Kucey, 1987, Kim et al., 1998, Wahid \& M ehana, 2000); em outros, o efeito ocorre apenas na produção de matéria seca (Freitas et al., 1997) ou na matéria seca e teor de fósforo (Chabot et al., 1996). Às vezes, com o mesmo microrganismo, são obtidos resultados diferentes. Kucey \& L eggett (1989) obtiveram respostas para o teor e conteúdo de $\mathrm{P}$ em casa de vegetação e para a produção de matéria seca e conteúdo deP em campo.

Em trabalhos de seleção, diferenças entre os isolados também são verificadas. Alguns isolados não apresentam qualquer efeito. Outros afetam apenas a produção de matéria seca sem alterar o teor defósforo e há os que aumentam a produção e o fósforo absorvido (Chabot et al., 1996; Freitas et al., 1997; Wahid \& Mehana, 2000).

Os isolados 310A e 251 apresentam características morfológicas do gênero Aspergillus, o isolado 62 de Penicillium, enquanto o isolado 189 apresenta características morfológicas e fisiológicas que o enquadram na família das Enterobacteriaceae (Silva Filho, 1998). Esses gêneros estão entre os mais citados na literatura como microrganismos solubilizadores de fosfatos que incrementam o fósforo absorvido e promovem o crescimento de plantas (Kucey, 1987, Kucey \& Leggett, 1989; Chabot et al., 1993; Kim et al., 1998; Rodriguez \& Fraga, 1999; Wahid \& Mehana, 2000).

As condições do ambiente são determinantes no sucesso da inoculação. Em condições de alto nível defertilidade, em queoteor defósforo nãoélimitante ao crescimento de plantas, os efeitos da sol ubilização são nulos. Estas condições predominaram nos tratamentos com fosfato monocál cico ou em condições de substratos preparados em campo, nos quais se percebem altos níveis de fertilidade. Efeitos positivos devem ser esperados apenas nas condições em que o el emento seja limitante. Observa-se que os resultados positivos da inoculação sobre a produção de matéria seca e conteúdo de $\mathrm{P}$ foram obtidos nos cultivos real izados em solos na presença de fosfato de Catalão ou na testemunha.

Assim, a importância destes microrganismos na disponibilização de fosfatos e sua utilização na substituição, total ou parcial, das adubações fosfatadas com pó de rochas, fosfatos, naturais ou solúveis, dependem do estabel ecimento das condições do modelo experimental utilizado e, conseqüentemente, das condições de campo onde for utilizado.

Segundo os resultados, os isolados 62, 189, 251 e 310A apresentam potencial para serem utilizados em processos de seleção, visando à produção de inoculantes que contenham microrganismos solubilizadores de fosfatos com o objetivo de substituir, total ou parcialmente, as adubações fosfatadas.

\section{CONCLUSÕES}

1. As condições nutritivas do meio (solo ou substrato) foram determinantes na demonstração dos efeitos da inoculação.

2. Os isolados $62,189,251$ e 310A apresentaram potencial para serem utilizados em processos de sel eção que visem à produção de inoculantes.

\section{LITE RATURA CITADA}

BRAGA, N.R.; MASCARENHAS, H.A.A.; BULISANI, E.A.;RAIJ , B. van; FEITOSA, C.T. \& HIROCE, R. Eficiência agronômica de nove fosfatos em quatro cultivos consecutivos de soja. R. Bras. Ci. Solo, 153:315-319, 1991.

CARDOSO, E.J .B.N. E cologia microbiana do sol o. In: CARDOSO, E.J .B.N.; TSAI , S.M. \& NEVES, M.C. Microbiologia do solo. Campinas, Sociedade Brasileira de Ciência do Solo, 1992. p.33-39.

CHABOT, R.; ANTOUN, H. \& CESCAS, M.P. Stimulation de la croissance du maïs et de la laitue romaine par des microorganismes dissolvant le phosphore inorganique. Can. J. Microbiol., 39:941-947, 1993.

CHABOT, R.; ANTOUN, H. \& CESCAS, M.P. Growth promotion of maize and lettuce by phosphate-solubilizing Rhizobium leguminosarum biovar phaseoli. Plant Soil, 184:311-321, 1996. 
EIRA, A.F. Solubilização microbiana de fosfatos. In: CARDOSO, E.J.B.N.; TSAI, S.M. \& NEVES, M.C. Microbiologia do solo. Campinas, Sociedade Brasileira de Ciência do Solo, 1992. p.33-39.

FREITAS, J.R.; BANERJ EE, M.R. \& GERMINA, J.J. Phosphatesolubilizing rhizobacteria enhancethegrowth and yield but not phosphorus uptake of canola (Brassica napus L.), Biol. Fertil. Soils, 24:358-364, 1997.

GOLDSTEIN, A.H. Bacterial solubilization of mineral phosphates: historical perspectiveand future prospects. Am. J. Altern. Agric., 1:51-57, 1986.

KIM, K.Y.;J ORDAN, D. \& MCDONALD, G.A. Effect of phosphatesolubilizing bacteria and vesicular-arbuscular mycorrhizae on tomato growth and soil microbial activity. Biol. Fertil. Soils, 26:79-87, 1998.

KUCEY, R.M.N. I ncreased phosphorus uptake by wheat and field beans inoculated with a phosphorus-solubilizing Penicillium biliji strain and with vesicular-arbuscular mycorrhizal fungi. App. Environ. Microbiol., 53:2699-2703, 1987.

KUCEY, R.M.N. \& LEGGETT, M.E. Increased yields and phosphorus uptake by westar canola (Brassica napus L.) inoculated with a phosphate-solubilizing isolate of Penicillium bilaji. Can. J. Soil Sci., 69:425-432, 1989.

KUNDU, B.S. \& GAUR, A.C. Rice response to inoculation with $\mathrm{N}_{2}$-fixing and P-solubilizing microrganisms. Plant Soil, 79:227-234, 1984.

MARX, D.H. The influence of ectotrofic mycorrhizal fungi on the resistence of pine roots to pathogenic infections. I. Antagonism of mycorrhizal fungi to root pathogenic fungi and soil bacteria. Phytopathology, 59:153-163, 1969.

NAHAS, E. Solubilização microbiana de fosfatos e de outros elementos. In.: SIQUEIRA, J .O.; MOREIRA, F.M.S.; LOPES, A.S.; GUILHERME, L.R.G.; FAQUIN, V.; FURTINI NETO, A.E. \& CARVALHO, J .G. I nter-relações fertilidade, biologia do solo e nutrição de plantas. Viçosa, Sociedade Brasileira de Ciência doSolo/Lavras-U niversidade Federal de Lavras/ DCS, 1999. p.467-486.

NARLOCH, C.; OLIVEIRA, V.L.; ANJ OS, J.T. \& SILVA FILHO, G.N. Respostas da cultura do rabanete à inoculação com fungos solubilizadores de fosfatos. Pesq. Agropec. Bras., 37:841-845, 2002.
RAIJ , B. van. Fertilidade do solo e adubação. São Paulo, Ceres, 1991. 343p.

RODRÍGUEZ, H. \& FRAGA, R. Phosphate solubilizing bacteria and their role in plant growth promotion. Biotechnol. Adv., 17:319-339, 1999.

SILVA FILHO, G.N. Solubilização de fosfatos pela microbiota do solo. Porto Alegre, Universidade Federal do Rio Grande do Sul, 1998. 140p. (Tese de Doutorado)

SILVA FILHO, G.N. \& VIDOR, C. Solubilização de fosfatos por microrganismos na presença de fontes de carbono. R. Bras. Ci. Solo, 24:311-329, 2000.

SILVA FILHO, G.N. \& VIDOR, C. Atividade de microrganismos solubilizadores de fosfatos na presença de nitrogênio, ferro, cálcio e potássio. Pesq. Agropec. Bras., 36:1495-1508, 2001.

SILVA FILHO, G.N.; NARLOCH, C. \& SCHARF, R. Solubilização defosfatos naturais por microrganismos isolados de cultivos de Pinus e Eucalyptus de Santa Catarina. Pesq. Agropec. Bras., 37:847-854, 2002.

SYLVESTER-BRADLEY, R.; ASAKAWA, N.; LA TORRACA, S.; MAGALHÃES, F.M.M.; OLIVEIRA, L.A. \& PEREIRA, R.M. Levantamento quantitativo de microrganismos solubilizadores de fosfatos na rizosfera de gramíneas e leguminosas forrageiras na Amazônia. Acta Amazôn., 12:1522, 1982.

TAHA, S.M.; MAHMOUD, S.A.Z.; HALIM EL-DAMATY, A. \& ABD EL-HAFEZ, A.M. Activity of phosphate-dissolving bacteria in Egyptian soils. Plant Soil, 31:149-159, 1969.

TEDESCO, M.J .; GIANELLO, C.; BISSANI, C.A.; BOHNEN, H. $\&$ VOLKWEIS, S.J. Análise do solo, plantas e outros materiais. 2.ed. Porto Alegre, Universidade Federal do Rio Grande do Sul, 1995. 174 p. (Boletim Técnico, 5)

WAHID, O.A.A. \& MEHANA, T.A. I mpact of phosphatesolubilizing fungi on the yield and phosphorus-uptake by wheat and fava bean plants. Microbiol. Res., 155:221-227, 2000.

WHITELAW, M.A. Growth promotion of plants inoculated with phosphate-solubilizing fungi. Adv. Agron., 69:99-151, 2000. 
L. ALVES et al. 